\title{
Effect of an Educational Program about Acute Respiratory Distress Syndrome on Critical Care Nurses' Performance
}

\author{
Marzoq Ali Ahmed ${ }^{1}$, Faker Ali Ahmed ${ }^{2}$, Mona Aly Mohammed ${ }^{3}$, Mervat Anwar AbdEl-Aziz ${ }^{3}$ \& Asmaa Aly \\ Mahgoub $^{4}$ \\ 1. Assistance Lecturer of Critical Care and Emergency Nursing, Faculty of Medicine and Health Sciences, Amran \\ University, Yemen. \\ 2. Professor of Chest diseases, Faculty of Medicine and Health Sciences - Sana'a University, Egypt. \\ 3. Assistance Professor of Critical Care and Emergency Nursing, Faculty of Nursing, Assiut University, Egypt. \\ 4. Lecturer of Critical Care and Emergency Nursing, Faculty of Nursing, Assiut University, Egypt.
}

\begin{abstract}
Background Literature review cited that, Acute respiratory distress syndrome (ARDS) is one of the major manifestations of multiple organ failure syndromes, and is a leading cause of death in the Intensive Care Unit. Aimed this study to evaluate the effect of that an educational program on nurse's performance about acute respiratory distress syndrome. Design a quasi-experimental (pre/post-test design). Setting critical care units at AlThawra Modern General Hospital Authority in Sana'a-Yemen. Method Sample was (75) critical care nurses that of all nurses working in a selected setting. The tool I: Pre /Post Nurses Questionnaire, tool II: Pre /Post Observation Checklist. Results: As regard age, of nurses were $>25$ years (53\%), the education level, the nursing diploma was the most $(72 \%)$, experience year of nurses had an experience of less than 5 years was $(65.3 \%)$. The implementation of the education program revealed the improvement of critical care nurse's knowledge, practice scores, and levels regarding acute respiratory distress syndrome with high statistical significance difference between pre and postimplementation programs, $(\mathrm{p}<0.001)$. Conclusion, it can conclude that implementing an educational program about acute respiratory distress syndrome care is highly effective in inducing improvement in nurses' related knowledge and practice.
\end{abstract}

\section{Keywords: ARDS, Critical Care Nursing \& Performance.}

\section{Introduction}

The acute respiratory distress syndrome (ARDS) seriously attacks the pulmonary function and threatens life because the lungs become incompetent and severe hypoxia develops. Without respiratory support, the patient is unlikely to survive. However, mechanical ventilation, which is "contraphysiological", can be deleterious in maintaining lung inflammation that characterizes the disease. (Courtin, et al., 2012).

The clinical burden of ARDS in intensive care units (ICUs) has not been lowered since a half-century ago. In a large observational study focused on understanding the global impact of severe acute respiratory failure in 29,144 patients admitted to ICUs, 3022 patients (10.4\%) fulfilled ARDS criteria, and the mortality rate was higher than $45 \%$ in severe ARDS. The high mortality of ARDS is associated with limited efficient therapeutic measures. Although our understanding of ARDS pathophysiology and pathogenesis has improved, the proven beneficial measures are still focused on management with ventilators. (Koh, 2017)

Acute respiratory distress syndrome occurred in $3.35 \%$ of patients with a mortality rate of about
66.6\%, dehiscence sternum and mediastinitis occurred in $1.6 \%$ with mortality $33.3 \%$, pneumonia in $2.79 \%$, atelectasis in $3.35 \%$, and pleural effusion in $2.22 \%$ and pneumothorax in $0.55 \%$. The most predisposing factors were massive blood transfusion, re-exploration for control of postoperative bleeding, cardiopulmonary resuscitation, and prolonged length stay in the intensive care unit at Al-Thawra Hospital, Cardiac center, Sana'a, Yemen. (Al-Qubati, et al., 2013).

A key role for the vital care nurse is early detection and interference of respiratory disorder. Therefore, with relevancy respiratory disorder, it's essential for vital care nurses to be knowledgeable of risk factors, assessment tools and protocols, and preventive ways. (Adam et al., 2017).

Nursing education across the United Kingdom is responding to dynamical desires, developments, priorities, and expectations in health and tending. Nurses UN agency acquire the data, skills, and behaviors that meet our standards are going to be equipped to fulfill these gift and future challenges, improve health and well-being and come near standards and quality, operating in a very vary of roles as well as professional person, educator, leader, and scientist. (O'Donnell \& Pike, 2010). 


\section{Significance of the study}

Acute respiratory distress syndrome and Sepsis in the United States both contribute significantly to the expanding burden of critical illness. Epidemiologic evidence suggests an incidence of 190,600 patients annually for ARDS and the mortality is present estimated at 25-38\%. (Mei, et al., 2016).

From the researcher's clinical experience, it has been observed that acute respiratory distress syndrome has numerous attendant risks and complications associated with it. The critical care nurses are close and continuous contact with patients and defect in knowledge and practice about acute respiratory distress syndrome. Therefore, they are uniquely placed to incorporate preventive and promotional strategies in the day-to-day care they provide. Therefore, they should have the knowledge, a good attitude and be skillful in dealing with these complications. Therefore, this study was carried out the to evaluated effect of an educational program on nurse's performance for a critically ill patient acute respiratory distress syndrome and it has been assumed that an intervention-training program would improve nurse knowledge and practice, which would reflect upon patient's condition, outcome, and prognosis.

\section{Aim of the study}

To evaluate the effect of that an educational program about acute respiratory distress syndrome on critical care nurses' performance.

\section{Hypothesis}

1. The mean performance scores of nurse post program will be higher than that of their preprogram scores. Tables $(\mathbf{2}, \mathbf{3})$

2. Positive correlation will be exist between nurses knowledge and practice score after application of the program. Table (4)

\section{Subject \& Methods \\ Researcher design}

The quasi-experimental research design was utilized in this study with one group pre-test and post-test approach was used to evaluate the effectiveness of an educational program for the present study.

\section{Settings of the study}

Data were collected (from February 2018 to July 2019) conducted for five days every week for twoshift duties at the medical intensive care unit, surgical intensive care unit and emergency intensive care unit at Al-Thawra Modern General Hospital Authority in Sana'a-Yemen.

\section{Sampling Technique}

The convenience sample was (75) nurses that of all nurses working in a selected setting and in the line with sample criteria selection bedside nursing staff working in ICU more than one year

\section{Study Tools}

Data pertinent to the study were collected, utilizing the following two tools:

The tool I: Pre /Post ARDS Nurses Questionnaire

Pre and post nurses questionnaire was developed by the researcher based on current national and international literature, adopted from (VINCENT et al., 2017), (Morton \& Fontaine, 2013)and tested by the researcher then used prior to the implementation of the program to measure the exact level of knowledge of nurses about acute respiratory distress syndrome care. The same tool was used immediately after the implementation of the program (immediate post-test), in addition to three months later to evaluate the gain knowledge after the intervention. To assess nurses knowledge

The questionnaire consist of:

Part one

Nurse's demographic characteristics of the study sample this part including age, level education, duration of experience and previous training course. To assess nurses demographic characteristic

\section{Part two}

Nurse's knowledge about acute respiratory distress syndrome care included (definition, etiology, risk factor, and pathophysiology, medical management, and nursing care). It consists of (74) items. The scoring system ranged from (0) for the incorrect answer and (1) for the correct answer. Covering six main parts:

Knowledge about anatomy and physiology of the respiratory tract (questions 1-5), definition and criteria (questions 6-10), risk factor and causes (questions 11-18), signs and symptoms, the pathophysiology of ARDS (questions 19-23), diagnosis and treatment (questions 24-33), and complications, nursing care and infection control of acute respiratory distress syndrome (questions 34-74) Score system

As regard pre and post, questionnaire sheet total score was 74 a degree classified to $>75 \%$ satisfactory and $<75 \%$ unsatisfactory

\section{Tool II: Pre/Post Observation Checklist}

The observation checklist was designed and tested by the researcher, based on reviewed relevant literature. This tool was used before (pre-test) and immediately (post-test) immediately after implementation and as well as three months later to evaluate the impact of an educational program on nurse's practice. (Lynn \& LeBon, 2011, \& Wiegand, 2011)

The researcher to evaluate the nurses' practice as regard respiratory distress syndrome care applied the observation checklist. Each item was observed, categorized and score into either (done correctly=2), 
(done incorrectly=1), (not done=0). The total of all items was 132.

\section{Score system}

As regard observation the checklist sheet, the total score was 264 a degree classified to above $75 \%$ satisfactory and below $75 \%$ not satisfactory

\section{Validity and Reliability}

The tools were tested for content related validity by a jury of five specialists in the field of critical care nursing and critical care medicine. Modification were carried out according experts judgment on clarity of sentences and appropriateness of contents. The reliability was tested for tool one (knowledge assessment tool), tool two (skills assessment tool) by using Cronbach's coefficient alpha $(r=0.817,0.794)$ respectively which is acceptable.

\section{A pilot study}

A pilot study was conducted on eight nurses (10\%) to test the feasibility, objectively and applicability of the tool and the necessary modification was done. The pilot sample was not included in the main study

\section{Development of the educational program:}

The aim of this program was to provide of critical care nurses with knowledge and practices regarding of ARDS. Developing and translated into Arabic the program by researcher related to literature. Panel of the five expert in field of critical care revised the content of program and educational booklet. Developing guided by reviewer of current and past, local and international related literature in the various aspects using books, articles, and periodicals, magazine. The educational booklet contents included theoretical as well as practical part

\section{The theoretical contents}

Contents were the focus on the lecture about:

Definitions, risk factors and causes, clinical features, pathophysiology, stage, and diagnosis, medical management includes ventilator strategies for ARDS, pharmacology therapy, nutritional therapy, complications, nursing care of acute respiratory distress syndrome.

\section{The practical content}

Contents were focused on demonstration and remonstration about how to apply procedures related acute respiratory distress syndrome included: respiratory assessment the total score was 19 items, daily endotracheal tube $\&$ mechanical ventilator care total score was 33 items. Nebulizer care procedure total score was 18 items: suction procedure total score was 25 items, arterial blood gases procedure total score was 24 items, and pulse oximetry procedure total score was 13 items.

Each procedure divided into four steps includes patient and nurse preparation, procedures, postprocedure, documentation.
Learning environment

- The program was conducted in the nursing room of each ICU setting.

Teaching methods

- Lecture, group discussion, demonstration, and redemonstration were the teaching method used.

\section{Teaching materials}

- Poster, PowerPoint, Video, and Booklets were the teaching materials used.

\section{Arranging the subgroup}

Since it was difficult to meet all nurses at the same time for program implementation and for better performance and understanding, the total sample was divided into 15 subgroups included 5 nurses each from different workplaces and years of experience.

\section{Method}

\section{The study was executed in 3 phases}

\section{Preparatory phase}

- Official permission to proceed with the proposed study was obtained from the head of the medical, surgical and emergency intensive care unit department as well as the hospital nursing director after explaining the aim and nature of the study.

- The tool one used in this study was developed in Arabic by the researcher based on reviewing the relevant literature.

- Permission for voluntary participation was obtained from nurses after the purpose and nature of the study were explained.

- Approval was obtained from the local ethical committee and the study was followed the common ethical principles in clinical research.

- Explain the aim and contents of the study to nursing supervisors and physicians to gain their cooperation and "allow the release of nurses to attend educational sessions during minimal workload activities.

\section{Ethical considerations}

The nature and purpose of the study were explained to nurses and was approved by the Ethical Committee in the faculty of nursing. Written consent was obtained from all nurses that are willing to participate. The study follows the common ethical principles in clinical research and confidentiality and anonymity were assured. Study subjects had the right to refuse to participate and or withdraw from the study without any rationale at any time and study subject privacy was considered during the collection of data.

\section{Implementation phase}

The program was implemented 15 times for the 15 sub-groups of nurses. Each group included five nurses who were exposed to five educational sessions to explain booklet knowledge as well as, to the preliminary one; each session takes about 30 minutes 
conducted for five days every week for two-shift duties. In an additional three sessions for practical procedures for each procedure 30 minutes for demonstration and redemonstration that need for 3 hours.

Preliminary session: in this session, the researcher met the participants and explained the objectives, contents, and evaluation of the program. Session I included: Anatomy and physiology of the respiratory system. Session II included: definition, causes, and risk factors of acute respiratory distress syndrome. Session III included: Pathophysiology and stages with clinical manifestation of acute respiratory distress syndrome. Session IV included: Diagnosis, medical treatment, of acute respiratory distress syndrome. Session V included: Nursing care plan and prevented the complication of acute respiratory distress syndrome.

\section{Practical session}

Practical procedures related acute respiratory distress syndrome demonstration and redemonstration for intensive care nurses. Session I included: Apply respiratory assessment and interpreted of Arterial blood gases 60 minutes. Session II included: Practiced of daily endotracheal tube $\&$ mechanical ventilator care and achieved of suction procedure 60 minutes. Session III included: Demonstrated nebulizer care procedure and Pulse oximetry procedure 60 minutes.

\section{Procedure}

- Data were collected (from February 2018 to July 2019) conducted for five days every week for two-shift duties .

- All nurses were interviewed during break time (30 minutes) in different shifts or before beginning of shift.

- At the beginning of program the objectives, contents as well as time schedule of the program were explained by the researcher for the participant to attain their active participation and cooperation during implementation of the program.

- Ask nurses to fill out the questionnaire sheet (tool I) to assess nurses" knowledge before application of the developed program about respiratory distress syndrome

- The researcher fill out the observation checklist to assess nurses' performance prior to application of the developed observation checklist of ARDS care (tool II).

- Each theoretical session was carried out in class to include all nurses. All the topics were presented in the form of power point program and poster as needed

- Every session was started first with discussion to assess nurse's feedback about the procedure (5 minutes) then training phase about the definition, indication, frequency of acute respiratory distress syndrome, and technique of the procedure (30 minutes).

- Researcher provided teaching material as videos about the procedure to help nurses during demonstrating it. Videos were presented before and after demonstration time.

- Each clinical session was repeated more than once in the same day and in the other day to be sure that every nurse reached accurate practices of the procedure.

- All nurses demonstrated for studied groups the procedure once or more under observation by a researcher in the lab to ensure correct procedure and assess the weak points.

- Each nurse of all studied groups obtained a copy of the educational program in Arabic and English language booklet included all theoretical and practical content.

- An open channel of communication was established between the researcher and nurses to verify any misconception, answer any question, and reinforce correct actions.

- In the last session, the researcher summarized and emphasized the important points of acute respiratory distress syndrome and mastering the practical steps

The last phase (the evaluation phase)

Evaluation of the program

The same pre-test study tools (questionnaire sheet (tool I), observation checklist (tool II) was used postimplementation for studied subjects in order to test the effectiveness of the program on nurses' knowledge and practice. Evaluation of knowledge and practice was done two times immediately post implementation of the educational program and post three months later. The comparison was done between pre implemented of an educational, immediately post program implementation as well as three months later.

Statistical Analysis

Data were collected and analyzed by computer program SPSS, version 25. Data expressed as mean, standard deviation, number, and percentage. Quantitative continuous data were compared using ANOVA test for comparisons among more than two groups and the paired t-test is used to determine significance for the numeric variable between two groups. Also, for correlation by Pearson Correlation. A probability level of 0.05 was adopted as a level of significance for testing the research hypothesis. 


\section{Results}

Table (1): Distribution for socio-demographic data of study sample $(n=75)$.

\begin{tabular}{|c|c|c|}
\hline Items & $\mathbf{N}$ & $\%$ \\
\hline \multicolumn{3}{|l|}{ Age Group } \\
\hline$<25$ years & 40 & 53.3 \\
\hline$>25-30$ years & 27 & 36.0 \\
\hline$>30$ years & 8 & 10.7 \\
\hline Mean \pm SD $($ range $)$ & \multicolumn{2}{|c|}{$26.39 \pm 3.39(20-38)$} \\
\hline \multicolumn{3}{|l|}{ Sex } \\
\hline Male & 30 & 40.0 \\
\hline Female & 45 & 60.0 \\
\hline \multicolumn{3}{|l|}{ Marital Status } \\
\hline Single & 41 & 54.7 \\
\hline Married & 34 & 45.3 \\
\hline \multicolumn{3}{|l|}{ Education level } \\
\hline Diploma & 54 & 72.0 \\
\hline Bachelor & 21 & 28.0 \\
\hline \multicolumn{3}{|l|}{ Experience year } \\
\hline$<5$ years & 49 & 65.3 \\
\hline$>5-10$ years & 22 & 29.3 \\
\hline$>10$ years & 4 & 5.3 \\
\hline Mean \pm SD(range $)$ & \multicolumn{2}{|c|}{$4.63 \pm 3.28(1-15)$} \\
\hline \multicolumn{3}{|l|}{ Training Session } \\
\hline Yes & 12 & 16.0 \\
\hline No & 63 & 84.0 \\
\hline \multicolumn{3}{|l|}{ Department } \\
\hline Medical Intensive Care Unit & 20 & 26.7 \\
\hline Surgical Intensive Care Unit & 20 & 26.7 \\
\hline Emergency Intensive Care Unit & 35 & 46.7 \\
\hline
\end{tabular}

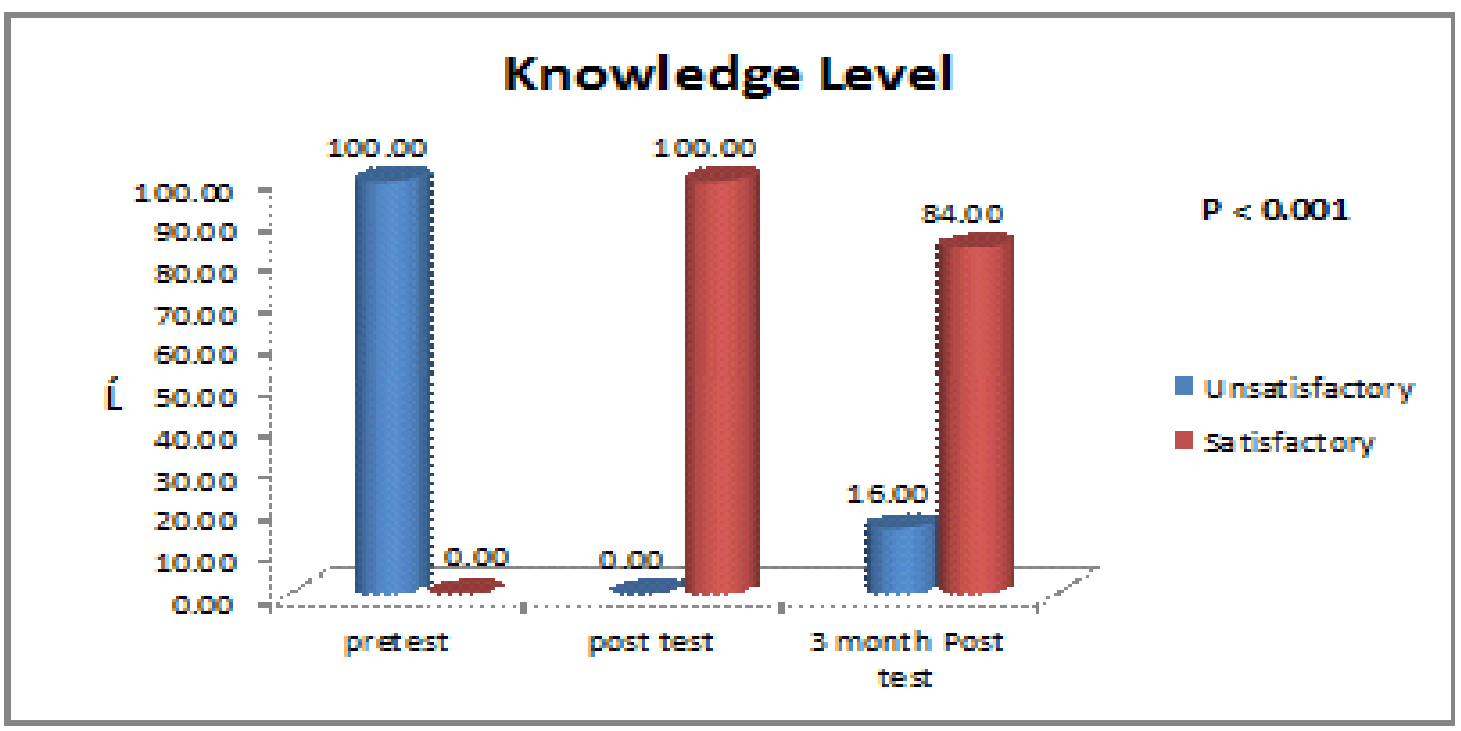

Fig. (1): Demonstration percentage of the knowledge level for nurses about ARDS during three program Phases (Pre, immediately post and 3-month post implementation) for Study Sample (n=75). 
Table (2): Distribution comparison of subtotal mean score the studied critical care nurses practice about ARDS related to respiratory system care during three program phases (Pre, immediately post and 3-month post implementation) for study Sample ( $n=75)$.

\begin{tabular}{|c|c|c|c|c|c|c|c|}
\hline \multirow{2}{*}{$\begin{array}{l}\text { Nurses practice } \\
\text { items }\end{array}$} & \multirow{2}{*}{ pretest } & \multirow{2}{*}{$\begin{array}{c}\text { immediately } \\
\text { post-test }\end{array}$} & \multirow{2}{*}{$\begin{array}{l}3 \text { Month } \\
\text { post }\end{array}$} & \multicolumn{4}{|c|}{ Comparison } \\
\hline & & & & P1. value & P2. value & P3. value & P4. value \\
\hline $\begin{array}{l}\text { Respiratory } \\
\text { assessment }\end{array}$ & $16.9 \pm 1$ & $34.9 \pm 1.2$ & $29 \pm 3.5$ & $<0.001 * *$ & $<0.001 * *$ & $<0.001 * *$ & $<0.001 * *$ \\
\hline $\begin{array}{l}\text { Daily endotracheal } \\
\text { tube \& mechanical } \\
\text { ventilator care }\end{array}$ & $21.8 \pm 3.3$ & $13.55 \pm 0.6$ & $10.76 \pm 0.91$ & $<0.001 * *$ & $<0.001 * *$ & $<0.001 * *$ & $<0.001 * *$ \\
\hline Suction & $19.13 \pm 2.8$ & $47 \pm 1.7$ & $38.67 \pm 1.54$ & $<0.001 * *$ & $<0.001 * *$ & $<0.001 * *$ & $<0.001 * *$ \\
\hline Nebulizer care & $14 \pm 1.3$ & $31.4 \pm 1$ & $27.2 \pm 1.9$ & $<0.001 * *$ & $<0.001 * *$ & $<0.001^{* *}$ & $<0.001 * *$ \\
\hline $\begin{array}{l}\text { Arterial blood } \\
\text { gases }\end{array}$ & $18.77 \pm 2.8$ & $44.85 \pm 2$ & $35.84 \pm 1.27$ & $<0.001 * *$ & $<0.001 * *$ & $<0.001 * *$ & $<0.001 * *$ \\
\hline Pulse oximetry & $8.64 \pm 2.52$ & $24.2 \pm 0.9$ & $19.64 \pm 1.5$ & $<0.001 * *$ & $<0.001 * *$ & $<0.001 * *$ & $<0.001 * *$ \\
\hline Total practice & $99.43 \pm 10.88$ & $241.8 \pm 6.1$ & $201.1 \pm 7.4$ & $<0.001 * *$ & $<0.001 * *$ & $<0.001 * *$ & $<0.001 * *$ \\
\hline
\end{tabular}

- ANOVA test - Paired T- test $\quad * *$ Significant difference at $p$. value $<0.05 \quad-P_{1}=$ per vs. immediately posttest

- $P_{2}=$ per vs. 3 month posttest $\quad-P_{3}=$ immediately posttest $v s .3$ month posttest

- $P_{4}=$ per vs. immediately posttest, 3 month posttest

Table (3): Correlation coefficient between Knowledge and Practice for Nurses during three program phases (pre-test, immediately post-test and 3-month post implementation test) for Study Sample (n=75).

\begin{tabular}{|l|c|c|c|c|c|c|}
\hline \multirow{3}{*}{ Correlations } & \multicolumn{3}{|c|}{ Total Knowledge } \\
\cline { 2 - 7 } & \multicolumn{2}{|c|}{ Pretest } & immediately post-test & \multicolumn{2}{c|}{ 3-month post } \\
\cline { 2 - 7 } & $\mathbf{R}$ & $\mathbf{P}$ & $\mathbf{R}$ & $\mathbf{P}$ & $\mathbf{R}$ & $\mathbf{P}$ \\
\hline Total Practice & 0.548 & $0.001^{* *}$ & 0.485 & $0.001^{* *}$ & 0.659 & $0.001^{* *}$ \\
\hline
\end{tabular}

**Statistically Significant Correlation at p. value $<0.05$

Table (4): Relationship between nurses knowledge Score about ARDS and their socio-demographic data during three program phases (pre, immediately post and 3-month post implementation) for Study Sample $(\mathbf{n}=75)$.

\begin{tabular}{|c|c|c|c|c|}
\hline \multirow{3}{*}{ Items } & \multicolumn{4}{|c|}{ Knowledge Score } \\
\hline & \multirow{2}{*}{$\mathbf{N}$} & pretest & Immediately post-test & 3 month Post \\
\hline & & Mean \pm SD & Mean \pm SD & Mean \pm SD \\
\hline \multicolumn{5}{|l|}{ Age group } \\
\hline - $\quad<25$ years & 40 & $22.78 \pm 5.8$ & $65.40 \pm 2.96$ & $57.53 \pm 3.49$ \\
\hline - $\quad>25-30$ years & 27 & $25.93 \pm 7.16$ & $67.41 \pm 3.36$ & $59.67 \pm 4.1$ \\
\hline - $\quad>30$ years & 8 & $25.75 \pm 3.6$ & $66.63 \pm 2.56$ & $58.5 \pm 3.81$ \\
\hline P. value & & 0.104 & $0.036 *$ & 0.077 \\
\hline \multicolumn{5}{|l|}{ Education Level } \\
\hline - $\quad$ Diploma & 54 & $21.07 \pm 4.12$ & $64.59 \pm 1.72$ & $56.37 \pm 1.85$ \\
\hline - $\quad$ Bachelor & 21 & $32.33 \pm 2.67$ & $70.52 \pm 1.72$ & $63.62 \pm 2.24$ \\
\hline P. value & & $0.001 * *$ & $<0.001 * *$ & $<0.001 * *$ \\
\hline \multicolumn{5}{|l|}{ Experience Year } \\
\hline - $\quad<5$ years & 49 & $23.39 \pm 5.86$ & $65.45 \pm 2.88$ & $57.61 \pm 3.47$ \\
\hline - $\quad>5-10$ years & 22 & $25.68 \pm 7.37$ & $67.95 \pm 3.34$ & $60.14 \pm 4.19$ \\
\hline - $>10$ years & 4 & $26.50 \pm 4.65$ & $66.75 \pm 2.36$ & $58.40 \pm 3.31$ \\
\hline P. value & & 0.284 & $0.007 *$ & $0.034 *$ \\
\hline \multicolumn{5}{|l|}{ Training Session } \\
\hline - $\quad$ Yes & 12 & $26.33 \pm 7.67$ & $67.67 \pm 3.47$ & $60.58 \pm 3.50$ \\
\hline
\end{tabular}




\begin{tabular}{|c|c|c|c|c|}
\hline \multirow{3}{*}{ Items } & \multicolumn{4}{|c|}{ Knowledge Score } \\
\hline & \multirow{2}{*}{$\mathbf{N}$} & pretest & Immediately post-test & 3 month Post \\
\hline & & Mean \pm SD & Mean \pm SD & Mean \pm SD \\
\hline - $\quad$ No & 63 & $23.84 \pm 6.06$ & $65.98 \pm 3.11$ & $57.97 \pm 3.78$ \\
\hline P. value & & 0.455 & 0.247 & 0.092 \\
\hline Department & & & & \\
\hline - $\quad$ Medical Intensive Care Unit & 20 & $26.50 \pm 5.14$ & $66.75 \pm 3.24$ & $59.05 \pm 2.3$ \\
\hline - $\quad$ Surgical Intensive Care Unit & 20 & $22.95 \pm 7.31$ & $66.45 \pm 3.06$ & $57.65 \pm 4.55$ \\
\hline $\begin{array}{ll} & \text { Emergency Intensive Care } \\
\text { Unit }\end{array}$ & 35 & $23.66 \pm 6.32$ & $65.86 \pm 3.24$ & $58.46 \pm 3.45$ \\
\hline P. value & & 0.159 & 0.581 & 0.513 \\
\hline
\end{tabular}

- T-test - ANOVA Test - ** Significant difference at p. value $<0.05$

Table (5): Relationship between nurses practice score about ARDS and their socio-demographic data during three program phases (pre, immediately post and 3-month post implementation) for Study Sample (n=75).

\begin{tabular}{|c|c|c|c|c|}
\hline \multirow{3}{*}{ Items } & \multirow{3}{*}{$\mathbf{N}$} & \multicolumn{3}{|c|}{ Practice Score } \\
\hline & & Pretest & Immediately post-test & 3 months post \\
\hline & & Mean \pm SD & Mean \pm SD & Mean \pm SD \\
\hline \multicolumn{5}{|l|}{ Age group } \\
\hline - $\quad<25$ years & 40 & $94.45 \pm 8.62$ & $241.33 \pm 6.33$ & $200.25 \pm 7.05$ \\
\hline - $\quad>25-30$ years & 27 & $104.81 \pm 9.52$ & $242.19 \pm 5.58$ & $203.85 \pm 7.71$ \\
\hline - $\quad>30$ years & 8 & $106.13 \pm 14.03$ & $242.75 \pm 7.53$ & $204.00 \pm 6.84$ \\
\hline P. value & & $<0.001 * *$ & 0.770 & 0.105 \\
\hline \multicolumn{5}{|l|}{ Education level } \\
\hline - $\quad$ High diploma & 54 & $94.83 \pm 8.87$ & $239.44 \pm 5.14$ & $198.59 \pm 5.24$ \\
\hline - $\quad$ Bachelor & 21 & $111.24 \pm 5.15$ & $247.81 \pm 4.07$ & $210.57 \pm 4.67$ \\
\hline P. value & & $<0.001 * *$ & $<0.001 * *$ & $<0.001 * *$ \\
\hline \multicolumn{5}{|l|}{ Experience year } \\
\hline - $\quad<5$ years & 49 & $94.14 \pm 8.78$ & $240.82 \pm 6.14$ & $200.43 \pm 6.93$ \\
\hline - $\quad>5-10$ years & 22 & $108.82 \pm 7.01$ & $243.45 \pm 6.14$ & $205.09 \pm 7.78$ \\
\hline - $>10$ years & 4 & $112.50 \pm 3.69$ & $244.50 \pm 4.12$ & $203.25 \pm 6.85$ \\
\hline P. value & & $<0.001 * *$ & 0.164 & $0.044 *$ \\
\hline \multicolumn{5}{|l|}{ Training Session } \\
\hline - $\quad$ Yes & 12 & $108.25 \pm 9.94$ & $241.17 \pm 7.80$ & $205.25 \pm 6.93$ \\
\hline - $\quad$ No & 63 & $97.75 \pm 10.29$ & $241.87 \pm 5.88$ & $201.32 \pm 7.38$ \\
\hline P. value & & $0.002 * *$ & 0.879 & 0.092 \\
\hline \multicolumn{5}{|l|}{ Department } \\
\hline - Medical Intensive Care Unit & 20 & $100.25 \pm 12.70$ & $241.95 \pm 7.13$ & $205.70 \pm 8.47$ \\
\hline - Surgical Intensive Care Unit & 20 & $102.30 \pm 8.99$ & $241.55 \pm 6.10$ & $201.15 \pm 5.07$ \\
\hline - Emergency Intensive Care Unit & 35 & $97.31 \pm 10.61$ & $241.83 \pm 5.73$ & $200.26 \pm 7.30$ \\
\hline P. value & & 0.246 & 0.970 & 0.025* \\
\hline
\end{tabular}

Independent T-test

- ANOVA Test ** Significant difference at p. value $<0.05$.

Table (1): This table describes of socio-demographic data for the studied sample consists of 75 intensive care unit nurses. As regard age, more than half of intensive care unit nurses were less than 25 years $(53 \%)$. As regard sex, nearly two-third of intensive care unit nurses were female $(60 \%)$. As regard to marital status, more than half of intensive care unit nurses were single $(54.7 \%)$. Regarding the education level, the nursing diploma was the most (72\%). As regards to experience year of nurses had an experience of less than 5 years was two-third $(65.3 \%)$. As regards previously attended training courses about ARDS was a high percentage no attended for training (84\%). As regard department 
was an emergency intensive care unit, nearly half the participants in the study $(46.7 \%)$.

Table (2): This table revealed that the mean total and subtotal nurses practice was the improvement in immediately post-program and decrease in three months post $(99.43 \pm 10.88,241.8 \pm 6.1 \& 201.1 \pm 7.4)$ respectively. In addition, there is a highly statistically significant difference between nurse's practice in relation to total and subtotal knowledge about ARDS during three program phases pre-test, immediately post-test and three-month post-test $(\mathrm{p}<0.001)$.

Table (3): This table represented the correlation coefficient between the total of knowledge and total of practice during three program phases. That shows there is a moderate positive correlation in preimplementation program $(r=0.548)$ with highly statistical significant difference $(p<0.001)$. In additional, there is moderate positive correlation in immediately post and three month postimplementation program $(r=0.485 \& r=0.659)$ respectively with highly statistically significant difference $(\mathrm{p}<0.001 \& \mathrm{p}<0.001)$ respectively

Table (4): This table shows that there is a statistical significant difference between knowledge score and age for more than 30 years in the immediate postprogram $(\mathrm{p}=0.036)$. Regarding marital status, there is a highly statistically significant difference with the knowledge score in the pre-implementation program ( $p<0.001)$. In addition, there is a highly statistically significant difference between the education level of nurses and the knowledge score in three program phases (pre, immediately post and 3-month post) (p $<0.001)$. As regarding experience years, there is a statistical significant difference with knowledge in immediately posttest and three months posttest $(\mathrm{p}=$ $0.007 \& p=0.034)$ respectively. As regarding the department, there is a highly statistically significant difference with the knowledge score in the preimplementation program $(\mathrm{p}=0.006)$.

Table (5): This table described the relationship between nurse's practice score they are sociodemographic, show that there is a statistical significant difference between practice score with age more than 30 years in the pre-implementation program ( $\mathrm{p}<0.001)$. Regarding the education level, there is a highly statistically significant difference between the education level of nurses and practice scores during three program phases (pre, immediately post and three-month post) ( $\mathrm{p}<0.001)$. As regards to experience years more than 10 years there is a statistically significant difference between experience years of nurses and practice score during three program phases (pre, and three-month postimplementation) ( $p<0.001 \& p=0.044)$ respectively. In addition, there is a highly statistically significant difference between training session attendance and practice scores in the pre-implementation program ( $\mathrm{p}$ $=0.002)$.

Figure (1): This figure reveals the difference between the levels of nurse's knowledge as regard pretest, immediately posttest, three months postimplementation program. There has been observed $(100 \%)$ unsatisfactory level in pre-implementation of the developed ARDS care and (100\%) satisfactory level immediately post-implementation of the developed ARDS care but a decrease of the satisfactory level to $(84 \%)$ in three-month postimplementation with highly statistically significant difference $(p<0.001)$

\section{Discussion}

Acute Respiratory Distress Syndrome (ARDS) is a clinical condition in which the lungs suffer severe irreversible, large-scale damage causing a grievous form of hypoxemic respiratory failure. (Sarkis, 2018) This education program can be incorporated into hospital education or in-service training for critical care nurses to strengthen their perceptions and knowledge of nutritional support in the ICU. This may improve the clinical outcomes of ICU patients.

(Kim \& Chang, 2019)

Statistical findings of the current study were present in three main parts. Part I: Descriptive statistical findings related to the demographic characteristics of critical care nurses (Table1). Part II: Delineated hypothesis testing for being support or not (Tables 2 , 3) and (Figures 3, 4, 5). Part III: clarified the additional study findings as, the response of critical care nurses to an educational program about respiratory distress syndrome care and the correlation between (critical care nurses score level, post-test knowledge and post observational checklist score) (Tables 4, 5) and (Figures 1,2).

Based on our results of the program implementation, it has been observed that intensive care unit nurse participant's age more than half of the nurses were less than 25 years. This might be attributed to the reluctance of the old nurses to work for the nonpayment of salaries because of the war in Yemen and as an alternative to them volunteers. The results of the present study agree with Hassan et al., (2018) who reported the age of the intensive care nurses more than half of them aged between $20-<25$ years. As regards to sex of the nursing participants, the present study was nearly two-third females. This in line with Mohammad, (2018) who documented nearly two-thirds of intensive care unit nurses participants in her study were females. Regarding level education, nursing has a diploma that was the most in the current study. This finding agreement with Abdullah et al., (2014) mentioned the majority of theme samples having diploma education. As 
regarding experience years in this, the study was more than half of nurses had less than 5 years of intensive care experience. In line with Mohammad, (2018), Kaur \& Charan, (2018) who reported nearly half of intensive care unit nurses experienced between $1-<5$ years.

Nurses knowledge regarding acute respiratory distress syndrome

In the current study, the results revealed that about nearly all of the intensive care unit nurse's unsatisfactory level knowledge before implementing the educational program. This reflects insufficient continuous education and especially training session. In addition, this might be the majority of nurses hold diploma degrees, not available of references and books if a theme has the book in English language difficulty nurses for reading because that not update of knowledge and sometimes lack staff orientation in the different intensive care unit.

In our study results, the implementation of the education program revealed the improvement of critical care nurse's knowledge score and level as regarding acute respiratory distress syndrome concept definition, criteria, risk factors, causes, signs and symptoms, diagnosis, treatment, nursing care, and infection control. The improvements were general sustained and provided evidence of the effectiveness of the educational intervention. This has showed to occur immediately post-implementation but revealed a little decline in the total mean of knowledge post three months later follow up. In addition, the result of the present study supported the stated hypothesis I that, there was improved of knowledge level at both immediately post and post three months later implementation as compared with pre implementation phase.

This present study proven by Bayomi et al., (2018) who concluded, implementing a nursing intervention program for the care of the patient with acute severe asthma is effective in inducing improvement in nurses' related knowledge and practice.

These results are an agreement with those of Abdou \& Dogham, (2016) who mentioned found that statistically significant differences between pre- and post-test scores for students' knowledge and showed improvement in knowledge gain after application of simulation-based learning about ARDS.

The present study supported by Mohammed, (2016) who mentioned there is a statistically significant difference between studied subjects (patients) pre and post-implementation of nursing guidelines.

This in line with Meherali et al., (2011) who reported the educational intervention significantly improved the knowledge level of the critical care nurse participants.
This agrees with Obaidan et al., (2018) who mentioned following the educational intervention, clinician knowledge of prone positioning increased, and confidence associated with performing the procedure improved significantly.

The findings of the current study were in line with Xiong et al., (2016) who documented After the mixed media education intervention, nursing students in the intervention group reported greater knowledge of standards precautions than did those in the control group.

In accordance with these results, Mohamed et al., (2018) who concluded the implementation of the nursing intervention protocol showed a significant improvement in the ICU nurses' level of knowledge and practice.

Nurses practices regarding acute respiratory distress syndrome

The present findings revealed an improvement in the practice score and level. Supported the stated hypothesis II that there was a highly significant difference between pre and post scores in relation to nurses' practice after completion of the educational program and concluded that participation in the educational program. The improvements were general sustained and provided evidence of the effectiveness of the educational intervention. This might be due to the achieved of the program, which many attributes to the fact that procedures were applying under the supervision and guidance of the researcher.

The present result agreement with AbdElbaky et al., (2018) who reported after the educational program, the majority of CCNs apply invasive procedures using EBP satisfactory at the post-program and follow up program phase. There was a statistically significant improvement of CCNs mean score in all dimensions related to the general performance postprogram and follow up program.

This in agreement with Hassan et al., (2018) who found the educational program improve nurse's practice regarding caring adult patients with an endotracheal tube and there was a statistically significant difference in total nurse practice during all program phases.

The current results supported by Mohammed \& Farag, (2019) who noticed the developed selfinstructional module showed effectiveness in improving nursing students' knowledge and practice. There was a significant difference between the mean post-test knowledge and practice scores of students after implementing it.

Moreover, this result in line with Hadian \& Sabet, (2013) who mentioned nurses' performance was poor and theoretical and practical education improved the performance. 
This results proven by Geravandi et al., (2018) who concluded their significant differences were observed in communication with patient, correct suctioning, compliance of aseptic techniques, the correct discharge of tube cuff, chest physiotherapy, the correct change positions, health food gavage, Backrub, prevent of foot drop, oral hygiene, and the eyes hygiene and protect the cornea had significant differences.

This finding in line with Day et al., (2001) a considerable lack of knowledge about various aspects of the suctioning procedure accompanied by poor practice was the highlight at the baseline assessment. However, it was encouraging to note that the experimental group showed considerable improvements in their knowledge and practice after an educational.

The present result proved by Kaur \& Charan., (2018) who concluded there was a significant difference between pre-test and post-test practice scores with improvement post educational program implementation for ICUs nurses.

The current results agree with Nteli et al., (2014) who reported shows that compliance can be increased by the implementation of a training program that will be ongoing and will be repeated at regular intervals based on the needs of staff.

\section{Correlation \& Relationship}

As regarding the correlation between nurse's knowledge and practice scores, in the preimplementation program, there is a positive correlation with a statistically significant difference. This reflects the importance of integration between theory and practice.

Rahmani et al., (2016) supported our results that reported the critical care nurses in both groups control and intervention used to deliver equal levels of care to those suffering from acute coronary syndrome before the scenario-based training with no significant difference was observe between the average scores of performance.

In addition, there is a moderate positive correlation related the post immediately that supported of Hypothesis III with a statistically significant difference between of them. This was proven the importance of integration between knowledge and practice.

Our finding study in the same line with Sheilini \& Devi, (2014) who reported that there is a significant relationship $(\mathrm{p}=0.011)$ between the knowledge of nursing students and skill.

This inline with Abd El-Aziz, (2014) shows that there was a significant positive correlation between the score of knowledge and score of skills $r=0.956$ post-education implementation for critical care nurses

\section{Conclusion}

Based on the finding of the current study, it can be concluded that implementing an educational program about acute respiratory distress syndrome care is highly effective in inducing improvement in nurses' related knowledge and practice level. There is a statistically significant difference between studied critical care nurses pre, post-implementation, and three months post-implementation.

\section{Recommendations}

From the foregoing conclusion, the following recommendation is suggested:

- Developing a system of periodical evaluation for nurses to determine strategies to update their knowledge and improving their practice.

- Encourage training courses about acute respiratory distress syndrome care that should be mandatory for newly employed nurses.

- Designing an educational handout about acute respiratory distress syndrome care must be provided to nurses to be used as a reference guide in their practice.

\section{Reference}

1. AbdElbaky, M., Mohamed, E., \& Nagib, R., (2018): Impact of Simulated Education program on Nurses' Performance of Invasive Procedure at Intensive Care Units: Evidence Based Practice. International journal of Nursing Didactics, 8(12), 13-20.

2. Abdou, F., \& Dogham, R., (2016): Impact of Using Simulation on Critical Care Nursing Students' Knowledge and Skills of Acute Respiratory Distress Syndrome. IOSR Journal of Nursing and Health Science, 5, 28-425.

3. Abdullah, M., Mohammed, W., \& Ismail, M., (2014)|: Nurses' knowledge and practices about administration of medications via nasogastric tube among critically ill patients. Journal of Education and Practice, 5(1), 147-159.

4. Adam, S., Osborne, S., \& Welch, J., (Eds.). (2017): Critical care nursing: science and practice. Oxford University Press.

5. Al-Qubati, F., Damag, A., \& Noman, T., (2013): Incidence and outcome of pulmonary complications after open cardiac surgery, Thowra Hospital, Cardiac center, Sana'a, Yemen. Egyptian Journal of Chest Diseases and Tuberculosis, 62(4), 775-780.

6. Audrey Courtin, Lucienne Sanchez, JeanClaude Sinquet, Philippe Gaudard, Jacob Eliet, Frédéric Barge, Pascal Colson (2012|): ARDS and ECMO, an update on critical care 
nursing, Open Journal of Nursing, 2. Pp. 301306, www.SciRP.org/journal/ojn

7. Bayomi, R., Taha, N., Zatton, H., \& Elshora, A., (2018): Effect of Nursing Intervention Program on Nurses Knowledge, Practices and Patients Outcomes with Bronchial Asthma. Journal of Nursing \& Care, 07(02), 1-6. https://doi.org/10.4172/2167-1168.1000448

8. Day, T., Wainwright, S., \& Wilson-Barnett, J., (2001): An evaluation of a an educational intervention to improve the practice of endotracheal suctioning in intensive care units. Journal of clinical nursing, 10(5), 682696.

9. EL-Aziz, M., (2014): Effect of educational program on nurses, knowledge and skills about oral care for traumatized patients. AAMJ, 12(1).

10. Geravandi, S., Soltani, F., Mohammadi, M., J., Alizadeh, R., Valipour, A., Hoseini, A., \& Ghomeishi, A., (2018): The effect of education on the nursing care quality of patients who are under mechanical ventilation in ICU ward. Data in brief, 16, 822-827.

11. Hadian, Z., \& Sabet, R., (2013): The effect of endotracheal tube suctioning education of nurses on decreasing pain in premature neonates. Iranian journal of pediatrics, 23(3), 340.

12. Hassan, A., (2018): Effect of Educational Program on Nurses' practice Regarding Care of Adult Patients with Endotracheal Tube. Port Said Scientific Journal of Nursing, 5(2), 142169.

13. Kaur, A., \& Charan, G., (2018): Study to Assess the Effectiveness of STP on Knowledge and Practice Regarding ABGs among ICU Nurses in Selected Hospitals at Jalandhar, Punjab. 8(3), 182-186.

14. Kim, H., \& Chang, S., (2019): Implementing an educational program to improve critical care nurses' enteral nutritional support. Australian Critical Care, 32(3), 218-222.

15. Koh Y., (2017): How to approach the acute respiratory distress syndrome: Prevention, plan, and prudence. Respiratory Investigation. 55(3), 190-195.

http://dx.doi.org/10.1016/j.resinv.2016.12.008 [Accessed December 17, 2018]

16. Lynn, P., \& LeBron, M., (2011): Skill Checklists for Clinical Nursing Skills: A nursing Process Approach (3rd Ed). Retrieved from LWW.com. 85-86

17. Meherali, S., Parpio, Y., Ali, T., \& Javed, F., (2011): Nurses' knowledge of evidence-based guidelines for prevention of ventilatorassociated pneumonia in critical care areas: a pre and post test design. Journal of Ayub Medical College, 23(1), 146.

18. Mei, S., dos Santos, C., \& Stewart, D., (2016): Advances in stem cell and cell-based gene therapy approaches for experimental acute lung injury: a review of preclinical studies. Human gene therapy, 27(10), 802-812.

19. Mohammad, E., (2018): Intensive Care Unit Nurses' Performance Regarding Caring Patients With Head Injury: An Educational Intervention. International Journal of Studies in Nursing, 3(3), 141.

20. Mohammed, H., \& Farag, A., (2019): Effect of Self-Instructional Module on Knowledge and Practice of Nursing Students Regarding Tube Feeding Insertion. Journal of Health, Medicine and Nursing, 4(1), 1-14.

21. Mohammed, I., (2018): The Impact of Training in Improving Nurses Performance in Mechanically Ventilated Patients in Khartoum and Alshaab Teaching Hospitals (20102014) (Doctoral dissertation, University of Gezira).15-25.

22. Mohammed, S., (2016): Nursing Guidelines and Its Effects on Nurses' Knowledge and Patient Safety Regarding Nosocomial Infection Control Measures in Burn Unit. IOSR Journal of Nursing and Health Science, 5(05), 06-16.

23. Morton, P., \& Fontaine, D., (2013). Critical Care Nursing A Holistic Approach (10th ed). China Library: Wolters Kluwer Health | Lippincott Williams \& Wilkins. 590 - 606

24. Nteli, C., Galanis, P., Koumpagioti, D., Poursanidis, G., Panagiotopoulou, E., \& Matziou, V., (2014): Assessing the effectiveness of an educational program on compliance with hand hygiene in a pediatric intensive care unit. Advances in Nursing, (2014, 7), $1-4$

25. Obaidan, A., Scott, J., Mirza, S., Aljoaid, A., Tailor, R., \& David L., Vines. (2018): Evaluation of a Training Method to Improve Knowledge and Confidence of Prone Positioning. Respiratory Care Education Annual, 27, 3-15. Retrieved from www.aarc.org

26. Pike, T., \& O'Donnell, V., (2010): The impact of clinical simulation on learner self-efficacy in pre-registration nursing education. Nurse Education Today, 30(5), 405-410. PP. 977. Available at: www.l.ww.com [Accessed October 26, 2018]

27. Rahmani, A., Mohammadi, A., \& Moradi, Y., (2016): Effectiveness of scenario-based education on the performance of the nurses in the critical cardiac care unit for patients with acute coronary syndrome. International Journal 
of Medical Research \& Health Sciences, 5(8), 218-224.

28. Taha, N., \& Ali, Z., (2013): Physical restraints in critical care units: impact of a training program on nurses' knowledge and practice and on patients' outcomes. J Nurs Care, 2(2), 1-9.

29. Vincent, J., Kochanek, P., Abraham, E., Fink, M., \& Moore, F., (2017): Textbook of Critical Care. In Journal of Chemical Information and Modeling (Seventh Ed, Vol. 1), 1689-1699.

https://doi.org/10.1017/CBO9781107415324.00 4

30. Wiegand, D., \& Carlson, K., (2011): AACN Procedure Manual for Critical Care,. In Critical Care Nurse (6th Ed, Vol. 1), 85-86. https://doi.org/10.4037/ccn2010432

31. Xiong, P., Zhang, J., Wang, X., Wu, T., \& Hall, B., (2017): Effects of a mixed media education intervention program on increasing knowledge, attitude, and compliance with standard precautions among nursing students: A randomized controlled trial. American journal of infection control, 45(4), 389-395. 